\title{
A TV MORENA EM PÁGINAS IMPRESSAS: VESTíGIOS DO NOTICIÁRIO SOBRE A CHEGADA DA TELEVISÃO NO ESTADO DE MATO GROSSO
}

THE TV MORENA ON PRINTED PAGES: TRACES OF THE NEWS ABOUT THE ARRIVAL OF THE TELEVISION IN THE STATE OF MATO GROSSO

\author{
Edvaldo Sotana* \\ edsotana11@gmail.com
}

RESUMO: Este artigo visa elucidar aspectos da história da televisão brasileira. De modo específico, aborda a TV Morena, instalada em Campo Grande, estado de Mato Grosso, em 1965. Notícias voltadas para despertar o interesse do leitor com relação ao novo meio de comunicação social e o material jornalístico sobre a instalação, a primeira transmissão e os momentos iniciais do seu funcionamento constituem o escopo da análise. No decorrer do texto, argumenta-se que a imprensa ressaltava o surgimento da emissora como um símbolo do mundo moderno que colocava a cidade na rota do progresso, aproximando-a de cidades como São Paulo e Rio de Janeiro. Para tanto, a pesquisa toma como fontes os jornais Correio do Estado, Jornal do Comércio e O Estado de Mato Grosso, no período de 1964 a 1966.

PALAVRAS-CHAVE: História da televisão, TV Morena, Estado de Mato Grosso.

ABSTRACT: This article aims to elucidate aspects of the Brazilian television history. It specifically approaches TV Morena, which is a television company set up in Campo Grande, in the state of Mato Grosso do Sul, Brazil, in 1965. News that are to call the reader's attention to the new media plus the journalistic material about the company's foundation, its first broadcast and the initial moments of its operation constitute the scope of the analysis of this research. Throughout the text, it is argued that the press emphasized the emergence of the station as a symbol of the modern world that would fit the city into the route of progress. In other words, Campo Grande would be able to be similar to big cities like São Paulo and Rio de Janeiro in terms of progress and modernity. Thus, this research relies on sources from 1964 to 1966, which are based on local newspapers like Correio do Estado, Jornal do Comércio and O Estado de Mato Grosso.

KEYWORDS: History of television, TV Morena, State of Mato Grosso.

Às sete em ponto, como tinha sido marcado, o salão do restaurante do Jockey Club fervilhava de gente. Em pontos estratégicos da cidade foram instalados 22 receptores nas vitrinas das dezessete lojas revendedoras de televisores, em quatro bares e no saguão dos Diários Associados, na rua Sete de Abril. No estúdio também estava tudo preparado ... (MORAIS, 1994, p. 502).

Assim descreveu Fernando Morais a inauguração da PRF-3, TV Tupi, de São Paulo, segunda emissora televisiva da América Latina. Em 18 de setembro de 1950, entrava no ar a televisão de Assis Chateaubriand, proprietário, à época, de uma cadeia de jornais e de emissoras de rádio. Além de narrar o momento, a biografia redigida por Morais também deu conta das primeiras experiências realizadas sob a batuta do proprietário dos Diários

\footnotetext{
* Doutor em História pela UNESP-Assis. Professor Associado do Departamento de História, Instituto de Geografia, História e Documentação (IGHD), Universidade Federal de Mato Grosso (UFMT). Professor do Programa de Pós-graduação em História da UFMT.
}

Hist. R., Goiânia, v. 23, n. 2, p. 115-136, mai./ago. 2018 
Associados, o investimento na compra e instalação de equipamentos, a construção da sede, o "esforço" para importação de televisores e a "expectativa estimulada" no público por "páginas e páginas de reportagens do Diário da Noite e do Diário de S. Paulo, que destacavam os menores detalhes daquela aventura" (MORAIS, 1994, p. 499).

Registrou, igualmente, o inusitado destino dado pelo empresário aos duzentos televisores importados dos Estados Unidos para a efetivação do projeto: dispôs a "caixa mágica" em alguns pontos estratégicos da capital paulista. Sua intenção era despertar a curiosidade dos telespectadores com as primeiras transmissões. Chama atenção o destino singular dado por Chateaubriand aos dois primeiros televisores que recebeu: um, deu de presente a Vera Faria, sua secretária particular, e o outro foi enviado para Eurico Gaspar Dutra, à época presidente da República. Para o presidente, o aparelho serviu como peça de decoração por quase um ano. O motivo: “a TV Tupi do Rio só seria inaugurada em 1951 e o alcance da imagem da TV Tupi paulista chegava ao máximo a cem quilômetros da capital, abrangendo poucas outras cidades" (MORAIS, 1994, p. 504).

Outras emissoras vieram a seguir. Em 1952, a TV Paulista, canal 5, foi inaugurada em São Paulo. No ano seguinte, a capital paulista teve acesso às imagens da TV Record. Além da TV Rio (Canal 13) e da TV Continental (Canal 9), ambas instaladas no Rio de Janeiro, as cidades de Belo Horizonte, Curitiba e Porto Alegre receberem emissoras televisivas na década de 1950 (MUSSOLIN NETO, 1988).

Ainda não era, contudo, o auge da televisão como meio de comunicação social no Brasil. Marcaram os anos iniciais o baixo número de aparelhos, a concentração dos canais nas regiões Sul e Sudeste e as dificuldades para as empresas televisivas obterem recursos advindos da publicidade, notadamente frente às emissoras de rádio e aos jornais, concorrentes bem posicionados no mercado publicitário. O rádio, aliás, estava "na sua fase áurea, sob a liderança da Rádio Nacional" (CAPARELLI, 1982, p. 23).

A precariedade de recursos técnicos e a improvisação nos programas ao vivo também foram características dos primeiros lances do novo empreendimento comunicacional (MUSSOLIN NETO, 1988). Como já aventado, o próprio alcance das transmissões era limitado:

Em sua primeira década a televisão só existia onde estavam erguidas as antenas de transmissão. Os telespectadores podiam captá-la num raio 
máximo de 100 quilômetros em torno do transmissor que gerava as imagens. Portanto, cada estação de TV tinha que prover a sua própria programação. A estrutura empresarial das emissoras era pouco comercial e a produção e [...] distribuição dos programas era marcadamente regional (BARROS FILHO, 2010, p. 31).

No período, havia apenas expectativa sobre a chegada da televisão em diversas regiões do interior do país. No estado de Mato Grosso, por exemplo, o próprio aparelho virou objeto de desejo dos consumidores antes mesmo da instalação das emissoras televisivas em Cuiabá ou Campo Grande. Ainda sem receber qualquer sinal de TV, em 1960, a Coletoria Federal de Cuiabá atraiu interessados para o leilão de um aparelho de fabricação norte-americana, marca Philco Predilect, modelo H-3408, de dezessete polegadas (O ESTADO DE MATO GROSSO, 13 mar. 1960, p. 03).

Mas a imprensa mato-grossense abordava a possibilidade de instalação de emissora televisiva na capital do estado. Em 1962, o Jornal do Comércio sugeriu aos leitores que a primeira emissora televisiva cuiabana seria a TV-Rádio A Voz d'Oeste, relatando, inclusive, o desembarque de material para montagem da torre retransmissora na cidade (JORNAL DO COMÉRCIO, 04 e 05 jul. 1962, p. 04). A Voz d'Oeste, contudo, não chegou a funcionar como emissora televisiva.

A partir de meados da década de 1960 foram instaladas as três primeiras emissoras televisivas no estado de Mato Grosso. Empresários ligados à distribuição de gás, atuantes no ramo desde 1955 e detentores da empresa Copagaz, os irmãos Eduardo, Nagib Elias e Ueze Zahran, vislumbraram um novo ramo de negócios. ${ }^{1}$ Ainda em 1963 , solicitaram a concessão de três emissoras televisivas para o estado. Campo Grande, Cuiabá e Corumbá foram as cidades por eles escolhidas. A jornalista Antonieta Reis Coelho, na época funcionária da Editora Martins, foi contratada para providenciar a documentação exigida no processo. Ela acompanhou todo o trâmite burocrático junto ao Conselho Nacional de Telecomunicações (Contel) (BARROS, 1997). Em entrevista, recordou o modo como o contato ocorreu:

[...] recebi um telefonema de Ueze Zahran pedindo-me que acompanhasse a documentação de um canal de televisão que o Grupo Zahran havia requerido para Campo Grande no então Conselho Nacional de

\footnotetext{
${ }^{1}$ Consta no trabalho de Toniazzo (2007) que, antes da Copagaz, os irmãos Zahran atuaram no comércio local. No início dos anos 1950, tentaram criar a Companhia Paulista de Gás. Sem conseguir atrair investidores, pleitearam, junto ao Conselho Nacional de Petróleo, o direito de distribuir GLP. Em 1955, foram autorizados a distribuir 30 toneladas de gás por mês para São Paulo, Goiás e Mato Grosso. O negócio avançou em 1961, com a autorização para montar uma engarrafadora na cidade de São Paulo.
} 
Telecomunicações, pois na ocasião não existia o Ministério das Comunicações. [...] Depois da minha aceitação o Sr. Ueze foi em seguida ao Rio de Janeiro e em minha casa, [...] Batemos o requerimento ao CONTEL pedindo a concessão do canal de TV. (DIÁRIO DE CUIABÁ, 15 dez. 2013)²

Os irmãos Zahran não foram, entretanto, os únicos interessados nas concessões. Conforme as memórias de Alencar (2002), os Diários Associados de Assis Chateaubriand participaram, sem sucesso, da concorrência. No caso específico de Campo Grande, órgãos impressos noticiaram outro interessado. Entre novembro de 1963 e abril de 1964, O Matogrossense informou sobre as ações do comerciante Nelson Borges para instalar uma emissora televisiva em Campo Grande, sem, contudo, apresentar os motivos de sua desistência (O MATOGROSSENSE, 06 nov. 1963, p. 01 e 08 e 03 set. 1964, p. 01) - tema este ainda não abordado pela investigação acadêmica.

Em outubro de 1965 foi outorgada a concessão da TV Morena. No Natal daquele ano, os campo-grandenses receberam as primeiras imagens geradas pela emissora. Dois anos depois, a TV Centro-América começou a funcionar, em fase experimental, em Cuiabá, indo ao ar oficialmente em fevereiro de 1969. Em 1970, tiveram início as transmissões da TV Cidade Branca, em Corumbá, fronteira com a Bolívia. ${ }^{3}$

Dentre elas, a TV Morena foi escolhida como objeto do presente artigo. Abordar o surgimento da emissora e, especificamente, o noticiário veiculado na imprensa escrita regional acerca da sua instalação, a primeira transmissão e aspectos iniciais do seu funcionamento são objetivos deste trabalho. Particularmente, interessam os significados atribuídos pelos jornais para a chegada da televisão ao estado de Mato Grosso. Para identificá-los, pesquisamos os periódicos Correio do Estado, Jornal do Comércio e O Estado de Mato Grosso entre 1964 e 1966. ${ }^{4}$ Outros jornais também foram consultados

\footnotetext{
${ }^{2}$ Disponível em: <http://www.diariodecuiaba.com.br/detalhe. php?cod =443588>. Acesso em: 23 jan. 2018.

${ }^{3}$ Vale lembrar que outras emissoras já funcionavam na região Centro-Oeste. É o caso, por exemplo, da TV Brasília, da TV Alvorada e da TV Nacional, emissoras instaladas, em 1960, para a inauguração da capital federal (FERREIRA, 2012; BARBOSA, 2010). Além disso, tem-se a experiência com a televisão em Goiânia. No final da década de 1950, a Rádio Anhanguera, de J. Câmara e irmãos, experimentou imagens televisivas num circuito fechado. Em 1961, foi inaugurada a TV Rádio Clube (depois TV Goiânia), integrante dos Diários Associados. Em outubro de 1963, a TV Anhanguera entrou definitivamente no ar (GODINHO, 2008).

${ }^{4}$ Apesar do recorte temporal definido, temas anteriores foram abordados para situar o intervalo de 15 anos entre o surgimento da TV e sua chegada em Mato Grosso, assim como para indicar a existência de expedientes semelhantes.
} 
pontualmente para obtenção de dados e elementos históricos visando compor o trabalho. São eles: O Matogrossense, Diário de Cuiabá e O Estado de S. Paulo. ${ }^{5}$

Convém, ainda, explicitar o período em que a "caixa mágica" começou a funcionar no Estado de Mato Grosso. Ampla campanha foi movida contra João Goulart, abriu caminho para o golpe civil-militar de 1964 e para instauração do regime militar (Cf. FERREIRA; GOMES, 2014). Em mais de duas décadas de regime, os homens da caserna deram "especial" atenção aos meios de comunicação. No caso específico da televisão, deve-se ressaltar o substancial investimento feito pelos militares em infraestrutura com objetivos de "acompanhar o atendimento da demanda de comunicações exigidas pela economia do país e promover a implantação de meios de comunicação com vistas à integração e Segurança Nacional" (CAMPARELLI, 1982, p. 60).

A pesquisadora Lúcia Maciel Barbosa de Oliveira (2001, p. 102) avaliou o papel dos meios de comunicação para implantação e sustentação do regime ditatorial nos seguintes termos:

\begin{abstract}
Os meios de comunicação exerciam papel fundamental para a consecução do binômio segurança e desenvolvimento, tanto para se atingirem os objetivos traçados quanto como arma estratégica básica para a segurança interna. Que outro meio, dado seu alcance, serviria melhor ao propósito da integração nacional que nos levaria à unidade almejada? A eficácia da televisão foi percebida como fundamental na internalização dos valores essenciais para a consecução do projeto proposto. Não à toa cuidou-se de seu desenvolvimento e regulamentação com vistas aos objetivos traçados e, importante, como elemento legitimador do regime (...)
\end{abstract}

Carlos Fico (1997, p. 117) também abordou a importância da televisão para atividade política e "soldagem do sistema ideológico" instaurado com o golpe civil-militar de 1964:

Um regime autoritário de supressão de liberdades, meios de comunicação de massa modernos e com larga cobertura nacional, agências de publicidade profissionalizadas e sequiosas das contas governamentais: que se poderia esperar de uma tal combinação de fatores? Precisamente a criação de um dos maiores sistemas de propaganda política de um governo autoritário da época contemporânea.

\footnotetext{
${ }^{5}$ Consideramos importante "fugir das armadilhas criadas pelo uso acrítico da memória dos envolvidos no processo de implantação da TV como fonte de pesquisa e considerar as articulações estabelecidas com políticos locais como fundamentais para o surgimento e crescimento da primeira emissora televisiva no estado de Mato Grosso nos primeiros anos do regime militar brasileiro" (SOTANA, 2014, p. 120). Não há, porém, espaço para discussão de tais aspectos neste artigo. Para obter informações sobre o assunto, consultar Sotana (2014).
} 
É nesse quadro histórico, portanto, que devemos inserir a injeção de recursos estatais em infraestrutura e tecnologia, a ampliação do número de emissoras televisivas e o crescimento vultuoso do número de aparelhos receptores no país, além do aumento da “ingerência do Estado na indústria da televisão" (HAMBURGER, 1998, p. 454).

\section{Das fontes: alguns elementos para compor um incipiente problema de pesquisa}

Certamente, a imprensa periódica pode figurar como fonte relevante de pesquisa para os interessados em conhecer a história da televisão brasileira. No entanto, diferentes aspectos precisam ser considerados para se pensar a relação entre imprensa e televisão. Adolpho Queiroz já salientou que há uma "associação de interesses para a publicação de notícias sobre a televisão no jornal", fato que cria "uma relação indissociável capaz de promover a legitimação da linguagem da televisão enquanto instrumento de poder" (QUEIROZ, 1993, p. 11). Segundo o autor, os jornais atuam como "elos decisivos" entre a televisão e o público e, ainda que tenham existência editorial independente das emissoras televisivas, "contribuem para que a televisão permaneça no exercício de sua plena hegemonia" (QUEIROZ, 1933, p. 13). Importa lembrar que os meios de comunicação estão num campo de concorrência e competição, como apontou o estudo de Jeanneney (1996).

Com base nas formulações de Pierre Bourdieu (2000, p. 174), torna-se fundamental acentuar que a concorrência e a competição entre os meios de comunicação assumem formas de luta pelo "poder simbólico de fazer ver e fazer crer, de predizer e prescrever, de dar a conhecer e de fazer reconhecer". Portanto, os agentes entram em luta

pela conservação ou pela transformação do mundo social por meio da conservação ou da transformação da visão do mundo social e dos princípios de di-visão deste mundo: ou, mais precisamente, pela conservação ou pela transformação das divisões estabelecidas entre as classes por meio da transformação ou da conservação dos sistemas de classificação que são a sua forma incorporada e das instituições que contribuem para perpetuar a classificação em vigor, legitimando-a (BOURDIEU, 2000, p. 173-174).

Como observou Bourdieu, existe concorrência entre os diferentes meios de comunicação para impor princípios de visão de mundo, apesar de haver certa homogeneidade nos interesses das diferentes mídias e na fabricação dos produtos midiáticos: "É assim que, nesse domínio como em outros, a concorrência, longe de ser automaticamente geradora de originalidade e de diversidade, tende muitas vezes a favorecer a uniformidade da oferta" (BOURDIEAU, 1997, p. 108, grifo do autor). 
A partir das formulações do sociólogo, é possível ressaltar que "os princípios de divisão servem para a luta dos agentes no(s) campo(s) aos quais se inserem" (MIRANDA, 2005, p. 78-79). Dessa forma, as palavras são eficientes armas nos embates simbólicos, já que "são a grande força motora e criadora de tais grupos, das quais dependem quase que totalmente, desde a mobilização até a existência em algum tipo de classificação, viabilizadora mesmo desta mobilização" (MIRANDA, 2005, p. 79).

Dito isso, é fundamental perguntar: por quais motivos a imprensa periódica torna a televisão - potencial meio de comunicação concorrente - , um componente da sua pauta jornalística?

Se considerarmos a carência ou a dificuldade de acesso aos documentos produzidos pelas emissoras ou aos produtos televisivos, bem como as condições técnicas dos arquivos (BUSETTO, 2011), a pesquisa com jornais se mostra alternativa profícua para os estudiosos da história da TV. Conforme as reflexões de Áureo Busetto (2011), outras opções também podem ser exploradas pelos investigadores ocupados com a história da televisão brasileira. São exemplos a consulta aos livros com as memórias dos agentes atuantes na produção televisiva, a produção de fontes orais, o manuseio de DVDs contendo material televisivo e que são vendidos no mercado, assim como o acesso aos sites de compartilhamento, como o Youtube.

Mesmo com dificuldade de acesso aos produtos audiovisuais e documentos internos das empresas televisivas, pesquisadores têm se ocupado com a história da TV brasileira e seus produtos. ${ }^{6}$ Emissoras foram tomadas como objeto pelos estudos de Mariana Mont'Alverne Barreto Lima (2003), Eduardo Amando Barros Filho (2010 e 2017), Eduardo de Campos Lima (2010), Osmani Ferreira da Costa (2012) e Wellington Amarante Oliveira (2017). A análise de programas também encetou inúmeras pesquisas acadêmicas. Estudos sobre Telecurso 2o Grau (OLIVEIRA, 2011), Programa Abertura (MAIA, 2014) Globo Repórter (PALHA, 2008), minisséries (KORNIS, 2001) e telenovelas (LEAL, 1986; ALMEIDA, 2001; HAMBURGER, 2005) são apenas alguns exemplos.

\footnotetext{
${ }^{6}$ Com relação as fontes para pesquisa histórica sobre a televisão em parte do Estado de Mato Grosso, sobretudo dificuldades de acesso e possibilidade de constituição de acervos documentais, consultar Sotana (2017)
} 
Com relação à história da TV Morena, temos os trabalhos de Gerson Luiz Martins (1999), Marcelo Vicente Câncio Soares (2006, 2011) e Gladis Salete Linhares Toniazzo (2007), além, é claro, de pesquisadores que analisaram programas dessa emissora, como Camila Dib Silva Jorge (2013), acerca da linguagem utilizada no telejornal MS TV 1a edição, e de Lucas Marinho Mourão (2013), que enfoca o programa MS Rural.

Dos trabalhos citados sobre a TV Morena, os jornais foram tomados como fontes para a produção do estudo apresentado por Câncio Soares (2006) em evento acadêmico e para a pesquisa de Toniazzo (2007). Ambos utilizaram os registros da imprensa para abordar, principalmente, a comercialização de aparelhos televisores e a programação da emissora nas décadas de 1960 e 1970. Toniazzo também tratou da matéria jornalística referente ao decreto presidencial que autorizou o funcionamento da emissora. A pesquisadora reconheceu a carência de documentos e indicou que jornais locais foram utilizados para embasar a "reconstituição histórica das emissoras". A despeito da importância do seu trabalho para pensarmos a constituição da Rede Matogrossense de Televisão, fica patente a função acessória atribuída aos jornais: “O uso dos jornais servirá para documentar os acontecimentos anteriores ao início das transmissões da TV Morena, bem como corroborar as informações obtidas nas entrevistas" (TONIAZZO, 2007, p. 22).

Convém salientar que os trabalhos citados pouco utilizaram acervos periódicos para tratar dos significados atribuídos pela imprensa à implantação da TV Morena em Campo Grande, Mato Grosso. Importa registrar também que a chegada da TV ao estado não foi pauta de jornais de circulação nacional como O Globo e Folha de S. Paulo. Apenas O Estado de S. Paulo noticiou um contrato firmado entre a Authentic e a TV Morena para aquisição de seis câmeras da marca Vidicon, de $38 \mathrm{~mm}(1$ 1 1/2"), como o "maior fornecimento de câmeras de TV, efetuado de uma só vez por uma fábrica brasileira" (O ESTADO DE S. PAULO, 17 set. 1965, p. 24). No mês seguinte, o periódico paulista divulgou a concessão outorgada pelo presidente Castelo Branco (O ESTADO DE S. PAULO, 15 out. 1965, p. 08). Nada foi publicado, porém, sobre a inauguração e as primeiras transmissões da emissora campo-grandense. Portanto, é justamente a TV Morena nas páginas de órgãos da imprensa periódica regional que o leitor encontrará a seguir 


\section{Significados impressos sobre a chegada da TV}

Antes mesmo de iniciar as transmissões, a TV Morena já era tema frequente nas páginas dos jornais publicados no estado de Mato Grosso. Em setembro de 1964, O Estado de Mato Grosso registrava expediente semelhante àquele utilizado por Assis Chateaubriand na década anterior. De acordo com o jornal, era significativa a "presença de espectadores diante da Televisão da firma Irmãos Zahran", bem como "a grande presença, nos escritórios da firma, de pessoas que estão adquirindo televisores". Ainda segundo a notícia, havia expectativa de atingir 1.500 aparelhos vendidos ao final daquele mês, pois, além da comercialização na loja, doze corretores percorriam a cidade, batendo de porta em porta, para vender os aparelhos - fato que sugeria que "mais uma iniciativa de arrojo será vitoriosa em nossa terra, pois a TV - Morena está tendo ótima aceitação" (O ESTADO DE MATO GROSSO, 15 set. 1964, p. 01).

Três meses depois, o jornal informava sobre a chegada de seiscentos aparelhos a cidade, o que "redobra em toda a população citadina a confiança de que dentro em breve a TV-MORENA estará em pleno funcionamento em Campo Grande" (O ESTADO DE MATO GROSSO, 10 dez. 1964, p. 03).

Por sua vez, na coluna intitulada "Ronda do Rádio", Garcez Costa escreveu uma nota sobre o ritmo com que se davam os preparativos para instalação da TV Morena. Em meio a outros assuntos, Costa fez um trocadilho com a mudança de canal antes mesmo de a emissora funcionar: “A TV Morena, a nova maravilha que surge na cidade está em acelerado ritmo de progresso e promete muito mais: começou no Canal 2 e já está no Canal 4. Progrediu muito, em pouco tempo" (JORNAL DO COMÉRCIO, 13 dez. 1964, p. 05).

Em janeiro do ano seguinte, $O$ Estado de Mato Grosso noticiava a chegada de televisores a Campo Grande: “a esta altura, ninguém mais tem dúvidas de que os irmãos Zahran serão bem sucedidos em sua arrojada iniciativa de brindar Campo Grande com essa maravilha que é a televisão" (O ESTADO DE MATO GROSSO, 07 e 08 jan. 1965, p. 01, grifos nossos).

Qualificação semelhante foi atribuída pelo Correio do Estado ao longo de todo o ano de 1965. Com a expectativa de instalação da TV Morena em Campo Grande, como a primeira emissora do estado de Mato Grosso, o periódico, fundado em 1955 e à época dirigido por 
José Barbosa Rodrigues, noticiava a chegada e venda de aparelhos televisores para a população local. O jornal registrou que o Grupo Irmãos Zahran adquiria, em São Paulo, aparelhos para atender "à vasta clientela" da emissora prevista para funcionar nos meses seguintes (CORREIO DO ESTADO, 22 jun. 1965, p. 01). Em julho de 1965, indicou mais um dos "tradicionais desfiles de veículos transportando nova parte (sic) de aparelhos de televisão". Na ocasião, os irmãos Zahran compraram outra leva de duzentos televisores em São Paulo para revenderem aos campo-grandenses (CORREIO DO ESTADO, 17 jul. 1965, p. 03). Matérias jornalísticas também tratavam da entrega dos aparelhos televisivos a "dezenas de famílias" que não desejavam "ficar de fora do arrojado lançamento dos filhos do 'saudoso' Elias Zahran" (CORREIO DO ESTADO, 2 ago. 1965, p. 02).

Vale observar que aparelhos televisores eram comercializados na Copagaz pelos idealizadores da TV Morena, como sugere o anúncio veiculado nas páginas do Correio do Estado sobre a venda ao custo de CR\$ 40.000 mensais (CORREIO DO ESTADO, 13 out. 1965, p. 03). Os anúncios foram veiculados desde o início do ano, inclusive com os primeiros indicando que apenas os aparelhos comprados na loja da família Zahran teriam assistência técnica garantida pela emissora (CORREIO DO ESTADO, 14, 16 e 19 jan. 1965, p. 03). No seu livro de memórias, Alencar (2002, p. 51) ressaltou que os irmãos Zahran abriram uma loja de televisores e logo passaram a montar os aparelhos: "Abriu lojas de televisores. Como eram caros e ruins, radicalizou: reconvocou o técnico que montará seus transmissores, Luís Rutman, e abriu uma fábrica". E atribuiu a seguinte fala a um dos idealizadores do projeto: "O nosso televisor, o Michigan, custava metade e pifava menos do que o de chassis frio da Philco, por exemplo, que era uma bomba"7.

Afora matérias e anúncios publicitários sobre a chegada e a comercialização de televisores, o signo da modernidade e a chegada do progresso à região sul de Mato Grosso foram temas abordados nos textos sobre a localização da emissora, as peças que integravam sua estrutura, a instalação da torre transmissora, a construção dos seus estúdios e do auditório. Intitulado "TV - MORENA transforma Panorama do Alto da Vila São Bento", um apologético texto jornalístico indicava o número de operários trabalhando nas obras dos

\footnotetext{
${ }^{7}$ Apesar de não ser objeto deste artigo, convém salientar que, na década seguinte, os empresários investiram na produção de componentes eletrônicos, criando, em 1978, a indústria Engezel, com objetivos de projetar e produzir equipamentos de telecomunicações, especialmente aqueles destinados às emissoras televisivas. Cf. Executivo - a revista de Mato Grosso do Sul, ano 2, n. 13, mar. 1985.
} 
estúdios, no espaço administrativo e nas instalações dos transmissores para transformar "o recanto bucólico dos Altos da Vila São Bento, Boa Vista e Castelo num verdadeiro centro de atividades construtivas", bem como assegurar "um serviço perfeito de transmissão das imagens aos lares da região" (CORREIO DO ESTADO, 28 jan. 1965, p. 01). As obras foram assim classificadas nas páginas impressas:

A arrojada iniciativa dos Irmãos Zahran em breve será uma realidade e demonstrará o pioneirismo autêntico destes campo grandenses que não hesitaram em realizar um empreendimento desta envergadura, numa demonstração de progresso, labor para a terra matogrossense. A TVMorena, canal 4, será, em breve, uma grandiosa realidade! (CORREIO DO ESTADO, 28 jan. 1965, p. 01).

O tema figurou em outro periódico da cidade. No Jornal do Comércio, Cleomenes da Cunha utilizou a coluna "Notícias sem manchete", substituta do espaço "Coluna por dois", para tratar das obras da TV:

Como campo-grandenses que somos, acreditamos na TV Morena. Acreditamos e prestigiamos aquele trabalho, pois sabemos que não é fácil a instalação de uma estação de TV no interior brasileiro. E quem discordar de nossa opinião que visite as obras da estação televisora e auditório que está sendo erguido nos altos da cidade. (JORNAL DO COMÉRCIO, 04 abr. 1965, p. 03)

A modernização da cidade com a chegada da televisão foi temática recorrente nas publicações imprensas nos meses seguintes (CORREIO DO ESTADO, 16 fev. 1965, p. 02; 20 fev. 1965, p. 07; 04 mar. 1965, p. 05; 09 abr. 1965, p. 01; 02 ago. 1965, p. 04). Anúncios publicitários chamavam atenção para a grandiosidade da obra e a modernização representada pela TV, colocando o estado ao lado de poucas regiões no país. Em fevereiro, uma peça publicitária ocupou quase uma página inteira para sentenciar: "Eloquente Demonstração de Progresso da 'Cidade Morena'” (CORREIO DO ESTADO, 06 fev. 1965, p. 01, 08 e 09; fev. 1965, p. 03). Outra, no mesmo mês, colocou em destaque a construção: "Você sabia que a TV-Morena ocupa uma área de 18.000 metros quadrados num dos pontos mais altos do município de Campo Grande?" (CORREIO DO ESTADO, 10 fev. 1965, p. 02). Mais um anúncio questionava: "Você sabia que somente 33 cidades do Brasil possuem estações de Televisão? Campo Grande, graças a você e à TV-Morena será a trigésima quarta" (CORREIO DO ESTADO, 17 fev. 1965, p. 04; 18 fev. 1965, p. 02; 19 fev. 1965, p. 03).

Rubens Ávila, outro redator da coluna "Notícias sem manchete", salientou o efeito de progresso conferido pela instalação de antenas receptoras nos mais diversos pontos da 
cidade: "As antenas de TV já começam a surgir nos telhados da cidade. É o progresso, simbolizado nas esguias antenas" (JORNAL DO COMÉRCIO, 12 fev. 1965, p. 03).

Além dessas colunas e anúncios publicitários, matérias jornalísticas também foram publicadas. Em abril de 1965, o Correio do Estado veiculou matéria de página inteira. $\mathrm{Na}$ ocasião, o periódico publicou extenso texto para indicar que o funcionamento de uma emissora televisiva demonstrava "grandeza e pujança desta Maravilhosa Metrópole do Oeste brasileiro". Evocando o "espírito progressista" responsável pela construção da cidade do futuro, a matéria reverenciou a iniciativa dos irmãos Zahran. Conforme o texto,

é de justiça que se ressalte, com os aplausos que bem merece, essa obra extraordinária, a que se propuseram dotar a maior cidade do Estado, os dinâmicos irmãos Zahran, que é a primeira Estação de Televisão a ser instalada em nosso Estado, a vitoriosa TV - Morena, canal 4, dando-lhes não apenas o testemunho de nossa admiração e dos nossos aplausos, mas principalmente o integral, irrestrito e indispensável apoio de que necessitam, para levarem a bom termo essa realização sem similar em nossa história. (CORREIO DO ESTADO, 19 abr. 1965, p. 13.)

E o texto prosseguiu, afirmando que uma parcela da população conhecia a televisão - "a parte evoluída, viajada, em periódico contato com os grandes centros do país" - e, por isso, tinha ciência da "envergadura" dos esforços que eram necessários para instalação de uma emissora televisiva, dos compromissos financeiros que precisavam ser assumidos, da complicada trama burocrática e de "recursos técnicos até então desconhecidos em nosso meio" (CORREIO DO ESTADO, 19 abr. 1965, p. 13). O progresso que representava a iniciativa e sua importância para o futuro da cidade preencheram as linhas finais da matéria:

[...] dar a Campo Grande esse extraordinário invento do mundo moderno, que pelo dinamismo daqueles valorosos comerciantes atinge pela primeira vez este colosso do Oeste do país, abrindo uma nova era de progresso para esta região e dando maior conforto através de uma recriação sadia às famílias campograndenses. (CORREIO DO ESTADO, 19 abr. 1965, p. 13)

Em maio, o jornal $O$ Estado de Mato Grosso registrava a expectativa em torno do funcionamento da emissora televisiva. Também noticiava o andamento das obras e o "modernismo" das instalações da empresa, de seus estúdios, da sua torre metálica e de seus receptores". (O ESTADO DE MATO GROSSO, 23 abr. 1965, p. 01)

O Correio do Estado voltou à carga, em agosto, com manchete em letras garrafais: "TV - Morena: Grande Auditório em Marcha”. Nela, ressaltou que a emissora levaria imagens aos domicílios dos telespectadores em breve, pois, com a proximidade de encerramento das 
obras "modernizantes" e "completas", os irmãos Zahran entregam aparelhos televisores a "dezenas de famílias que não querem ficar de fora do arrojado lançamento" (CORREIO DO ESTADO, 02 ago. 1965, p. 03).

Porém, apenas em outubro de 1965, o Decreto no 56.977, assinado pelo então presidente Castelo Branco, autorizou a concessão do canal de televisão pleiteado para Campo Grande. Conforme registro da imprensa, a cidade teria a "primazia em televisão no Estado" (CORREIO DO ESTADO, 09 abr. 1965, p. 01). Dias depois, o Correio do Estado veiculou matéria com o título impresso em caixa alta: "TV-MORENA ESTÁ LEGAL: CASTELO BRANCO ASSINOU DECRETO PERMITINDO IMAGEM NO AR". No corpo da notícia, destacava que

os Irmãos Zahran continuam trabalhando nas duas mais importantes cidades matogrossenses, visando, como objetivo imediato, pôr em funcionamento as duas Estações Televisoras que se propuseram instalar em nosso Estado, num trabalho pioneiro capaz de honrar o espírito progressista da gente matogrossense. (CORREIO DO ESTADO, 16 out. 1965, p. 04)

Transmissões experimentais foram realizadas nas semanas seguintes. Consta no Correio do Estado que a "fase experimental" foi necessária porque o "trabalho das instalações" estava "sendo feito com o mais absoluto rigor técnico" - momento que seria passageiro, habilitando a cidade a ter "sua televisão funcionando a pleno e com perfeição" próximo do Natal. (CORREIO DO ESTADO, 24 nov. 1965, p. 01)

Nessa fase, as imagens eram transmitidas a partir de um estúdio improvisado na residência de Jorge Zahran. Elas eram "obtidas com um telecine rudimentar para cerca de uma dezena de televisores em pontos estratégicos da cidade, objetivando com isso despertar o interesse da comunidade para o advento da televisão" (ZAHRAN, 1990, p. 17).

Colunistas também registravam o funcionamento experimental da televisão. Aguinaldo Alves Faria, redator da coluna "Notícias sem manchete", por exemplo, salientou que a televisão estava "alegrando os lares campo-grandenses". Ele ressaltou: "O funcionamento é, ainda, em caráter experimental, devendo entrar em sua programação normal no próximo dia 24 . Vale a pena ver a imagem e ouvir o excelente som, a partir das 20 horas, todos os dias". (JORNAL DO COMÉRCIO, 21 dez. 1965, p. 03).

Mas somente em 24 de dezembro de 1965 ocorreu a primeira transmissão oficial da emissora campo-grandense. Além da participação de Antonio Mendes Canalle, prefeito à 
época, o evento contou com a benção do bispo Dom Antônio Barbosa, parcialmente interrompida em razão da quinta queda de transmissão de energia elétrica no dia (ZAHRAN, 1990).

Problemas no fornecimento de energia elétrica na cidade não datam da inauguração da TV. Segundo pesquisa de Andrey Martin (2016), na segunda metade da década de 1950, os periódicos associavam geração e fornecimento de energia elétrica ao progresso de Mato Grosso, sem, contudo, deixar de apontar para a escassez ou a constante falta de energia elétrica em cidades como Campo Grande. De acordo com o estudioso, mesmo com a tentativa de ampliação do parque energético na "esteira do ideal desenvolvimentista do período", a "expansão do setor e a proposta de criação de projetos, como a CEMAT, Centrais Elétricas Mato-Grossenses S/A, pelo então Governador Fernando Correa da Costa", a realidade energética era marcada por cotidianas reivindicações de melhorias por determinados setores da sociedade (MARTIN, 2016, p. 26).

Em princípios da década de 1960, a situação ainda era descrita nas páginas da imprensa. Em tom alarmante, O Matrogrossense sentenciava: "Campo Grande ameaçada de retornar ao período das trevas" (O MATOGROSSENSE, 14 out. 1963, p. 03). Em 1963, a solução também foi anunciada nas páginas da imprensa. Na primeira página d'O Estado de Mato Grosso foi celebrado o acordo entre Fernando Correa da Costa, governador do estado, e a Aliança Para o Progresso ${ }^{8}$, que prometia emprestar 9 milhões de dólares para financiar "um vasto programa de eletrificação em Mato Grosso" (O ESTADO DE MATO GROSSO, 06 jun. 1963, p. 01). Esse montante de recursos parece não ter solucionado o problema, como mostrou a situação vivenciada na inauguração da TV.

Mesmo com os problemas de fornecimento de energia e com o sinal circunscrito a Campo Grande, a TV Morena continuou a funcionar. Um ano depois das primeiras imagens, a impressa escrita ainda discorria sobre seu o significado para a região, além, obviamente, de tratar de outros temas que transcendem o objeto deste artigo. ${ }^{9}$

\footnotetext{
${ }^{8}$ Programa criado pelos Estados Unidos para acelerar o desenvolvimento socioeconômico da América Latina e formalizado em 1961 com a Carta de Punta del Este, assinada por mais 22 países, entre eles o Brasil. Um dos objetivos do governo estadunidense era formar aliança para contrapor-se ao que qualificava como agressão imperialista da União Soviética e de Cuba à região.

${ }^{9}$ Como exemplo, tem-se a instalação de torres retransmissoras em cidades do sul do estado de Mato Grosso, a programação televisiva e a aquisição de equipamentos.
} 
Visando motivar cuiabanos a adquirir seus aparelhos receptores - uma das condições para instalação da segunda emissora televisiva do estado - , uma exposição com fotografias da TV Morena foi montada no saguão do Banco do Estado de Mato Grosso em Cuiabá e noticiada pelo jornal O Estado do Mato Grosso. A mesma matéria veiculou ofícios contendo opinião de telespectadores a partir do contato que tiveram com a TV Morena, uma estratégia para despertar a "consciência do valor desse fabuloso empreendimento", tanto no visitante da exposição quanto no leitor do jornal. Endereçados a Antonieta Reis Coelho, os ofícios enfatizaram a nitidez e a perfeição da imagem e do som, como sugere o documento assinado pelo tenente-coronel Hélio Jesus Fonseca, comandante do 16은 Batalhão de Combate, ou como registrou Raul Santos Costa, da diretoria de expediente do governo do estado, ao colocar que as imagens eram reais e nada deviam "às do Rio de Janeiro e São Paulo" (O ESTADO DE MATO GROSSO, 25 dez. 1966, p. 15). Já Américo Texeira Paes de Barros considerou o empreendimento "de real utilidade para o desenvolvimento duma cidade" (O ESTADO DE MATO GROSSO, 25 dez. 1966, p. 15).

Por sua vez, o engenheiro civil Elzio Francisco Calabria tratou do edifício que abrigava a TV (figura 1) e dos seus equipamentos. Antes, porém, ressaltou sua felicidade em poder falar sobre "esse grupo de mato-grossenses, que vencendo todas as dificuldades, vem realizando essa grande obra que elevará Mato Grosso cada vez mais no consenso dos demais Estados do Brasil”. Especificamente, classificou a construção como "bela e magnífica obra de engenharia" e descreveu as instalações e equipamentos do seguinte modo: "torre de transmissão com $60 \mathrm{mts}$, equipamentos eletrônicos de primeira categoria, pessoal técnico devidamente aperfeiçoado, estúdios completos". No fim do documento, acentuou que tudo estava "perfeito", o que era "motivo de orgulho e vaidade para todos nós matogrossenses" (O ESTADO DE MATO GROSSO, 25 dez. 1966, p. 15). 


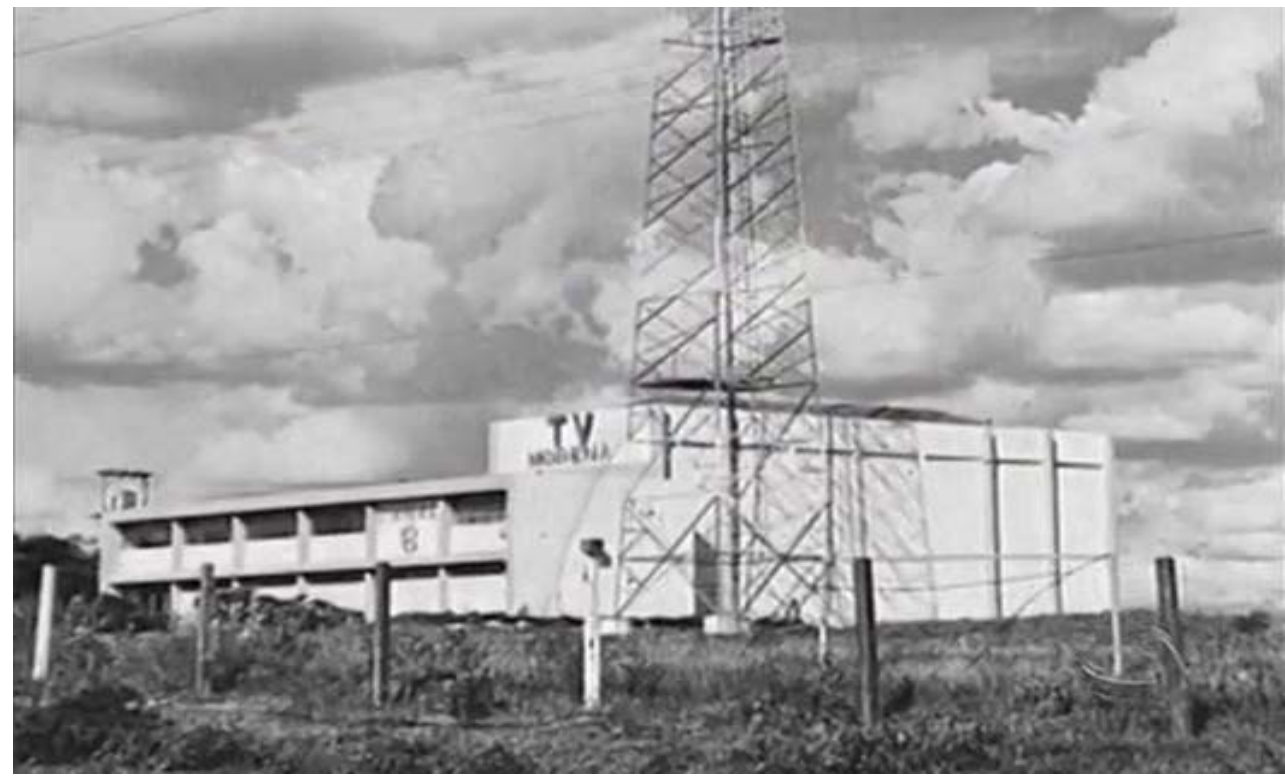

Figura 1 - Primeiro prédio da emissora Fonte: Rede Globo (2017)

As instalações também foram objeto do ofício enviado por Gastão Müller e publicado no jornal. Eleito suplente de deputado pela Aliança Renovadora Nacional (Arena) em 1966, o sobrinho de Filinto Müller registrou sua admiração "com o monumental prédio que foi edificado pelos irmãos Zahran para abrigar o notável empreendimento". Além de demonstrar sua admiração, o político advogava a necessidade de Cuiabá, urgentemente, "gozar da maravilha que é a televisão, sob todos os prismas" (O ESTADO DE MATO GROSSO, 25 dez. 1966, p. 15). O "progresso" que representava a chegada da televisão foi tema do ofício enviado por Leal de Queiróz, à época secretário do Interior e Justiça do estado de Mato Grosso, e publicado no jornal, pois, inaugurar em Cuiabá emissora semelhante a que ele conhecera em Campo Grande era tarefa "audaciosa" e que "retrata o progresso que aguarda a região norte mato-grossense" (O ESTADO DE MATO GROSSO, 25 dez. 1966, p. 15).

Afinal, para o órgão cuiabano, a capital do estado devia ser brindada com a chegada da TV, pois o moderno invento que apontava para o progresso da região não devia ser primazia de Campo Grande, polo econômico e político do sul do estado.

\section{Considerações finais}

Este artigo abordou o noticiário veiculado na imprensa escrita com vistas a despertar expectativa nos leitores acerca da televisão, bem como os textos sobre a instalação e a primeira transmissão da TV Morena. Também investigou os significados atribuídos pela imprensa para a chegada da televisão no estado de Mato Grosso. 
Importa lembrar que, durante muito tempo, o então estado de Mato Grosso foi tomado como antítese de progresso e civilização. Signos e símbolos foram mobilizados para classificá-lo como espaço de barbárie e marcado pelo atraso. Entre meados do século XIX e início do século $X X$, viajantes estrangeiros, intelectuais e dirigentes brasileiros produziram um conjunto de representações negativas e preconceituosas sobre a região e sua população. De acordo com Galetti (2000, p. 26-27), as representações visavam construir "uma fronteira entre civilização e barbárie dentro do próprio território nacional, que urgia fosse superada a fim de acelerar o progresso do país". Para a pesquisadora, as representações engendradas

enxergavam Mato Grosso pela mesma matriz das concepções ocidentais de progresso e civilização e pelas mesmas lentes das teorias evolucionistas e raciais que dominaram os horizontes ideológicos e culturais entre fins do século XIX e inícios do século XX. Mas, há também uma diferença de fundo entre estes três olhares, produto das relações distintas que mantinham com o seu objeto de observação. Assim, visto pela ótica dos viajantes estrangeiros, Mato Grosso era concebida como uma região ainda próxima da barbárie [...] os brasileiros elaboraram imagens ambíguas acerca de Mato Grosso: valorizado negativamente em razão das distâncias geográficas, históricas e culturais que o separavam do mundo e do Brasil civilizado, também o era positivamente como sertão e fronteira da pátria, noções fundamentais para a própria ideia de nacionalidade brasileira no período em foco. [...] Quanto aos mato-grossenses, compartilhando desta visão ambígua sobre a terra natal, manifestaram um profundo mal estar cultural face a uma identidade estigmatizada pela barbárie (GALETTI, 2000, p. 27-28, grifos da autora).

Ainda para a pesquisadora, tais representações caracterizaram a região como "confins do mundo civilizado" e da nação brasileira, além de subsidiarem "os esforços dos mato-grossenses no sentido de alterar esta definição de sua identidade" (GALETTI, 2000, p. 28).

Inúmeras ações foram empreendidas na tentativa de demonstrar o progresso chegando ao estado de Mato Grosso. A modernização da capital mato-grossense entre as décadas de 1930 e 1940 foi objeto de política pública do governo estadual. A remodelação da Avenida Getúlio Vargas e as chamadas obras públicas integraram o projeto de (re)urbanização e "modernização da cidade" na gestão do interventor Júlio Strübing Müller (LION, 2016).

Além das ações institucionais, a propaganda também foi realizada com intuito de extirpar o estigma da barbárie como característica do estado. Eduardo Salgueiro (2011, p. 12) apontou, por exemplo, o intuito da revista Brasil-Oeste em "tornar visível o centro-oeste 
do Brasil (especialmente Mato Grosso)" para "atrair investidores e fazer prosperar essa região". Entre 1956 e 1967, o periódico circulou nacionalmente e veiculou material jornalístico que evidenciava "as riquezas e potencialidades do Estado de Mato Grosso", assim como determinado ideal de progresso e projeto de colonização.

É nesse quadro histórico que devemos compreender a veiculação de representações jornalísticas sobre a primeira emissora televisiva do estado. A partir da pesquisa, foi possível constatar que foram construídas representações sobre a televisão como símbolo de progresso para a região, aproximando-a do Sudeste brasileiro. A instalação da TV Morena significava, segundo os jornais pesquisados, a modernização de parte do estado de Mato Grosso. Para a imprensa, a chegada da televisão à cidade era fruto da "arrojada" iniciativa dos irmãos Zahran. "Obra extraordinária", "espírito progressista", "demonstração de progresso" e "realização sem similar na história" são apenas alguns atributos usados para definir o "extraordinário invento do mundo moderno", responsável por apresentar o futuro para Campo Grande, equiparando-o às metrópoles nacionais.

É igualmente relevante ter um olhar crítico para tais representações. Certamente, o ideal de progresso e os símbolos da modernidade e de modernização do estado não devem ser tomados acriticamente pelo historiador. Convém recorrer às reflexões de Walter Benjamin, notadamente para termos cuidado ao tomar o progresso e os aparatos tecnológicos como forças que impelem a história para o futuro, fazendo o homem marchar em frente, em detrimento das ruínas do passado, assim como é premente discutir a noção de tempo própria dessa perspectiva, posto ser homogênea, cronológica, linear e evolutiva. Como Benjamin (1987, p. 232) colocou: "os adivinhos que interrogavam o tempo para saber o que ele ocultava em seu seio não o experimentavam nem como vazio nem como homogêneo".

Outro registro também parece necessário. Concordamos com os argumentos de Mariana Barreto (2008) ao estudar o surgimento da televisão no estado do Ceará, pois a pesquisadora lembra que os acontecimentos passados no eixo Rio-São Paulo não podem ser tomados como nacionais, como "ocorridos no país ao mesmo tempo" e sem atribuir importância às particularidades locais. Cuidado teórico à parte, a pesquisadora observa que a televisão foi fundamental para "atender os anseios de uma elite ávida por progresso, desenvolvimento e enriquecimento cultural" (BARRETO, 2008, p. 156). 
De certa forma, os jornais criavam familiaridade entre o leitor e a "caixa mágica", alimentavam expectativas e atribuíam significados à primeira emissora televisiva do estado de Mato Grosso num peculiar momento histórico, entendido como de aumento da "ingerência do Estado na indústria de televisão" e no qual as "telecomunicações" passaram a ser "consideradas estratégicas na política de desenvolvimento e integração nacional do regime" (HAMBURGER, 1998, p. 454). Certamente, é uma temática relevante para os pesquisadores interessados na mídia em geral, especialmente na história da televisão no Centro-Oeste brasileiro no decorrer do regime militar. Uma lacuna a ser explorada!

\section{FONTES}

Correio do Estado (194-1966)

Diário de Cuiabá (2013)

Executivo - a revista de Mato Grosso do Sul (1985)

Folha de S. Paulo (1965)

Jornal do Comércio (1964-1966)

O Estado de Mato Grosso (1960-1966)

O Estado de S. Paulo (1965)

O Globo (1965)

O Matogrossense (1963-1965)

\section{REFERÊNCIAS BIBLIOGRÁFICAS}

ALENCAR, José Roberto de. Muita sorte e pouco juízo. São Paulo: Ateliê Editorial, 2002.

ALMEIDA, Heloísa Buarque. Muito mais cousas: telenovela, consumo e gênero. Tese (Doutorado em Ciências Sociais) - Universidade Estadual de Campinas, 2001.

BARBOSA, Marialva. Imaginação televisual e os primórdios da TV no Brasil. In: RIBEIRO, Ana Paula Goulart; SACRAMENTO, Igor; ROXO, Marco. História da televisão no Brasil: do início aos dias de hoje. São Paulo: Contexto, 2010. p. 15-35.

BARETTO, Mariana Mont'Alverne. TV Ceará: processo de modernização da cultura local. Revista Pós Ciências Sociais. São Luís, v. 5, n. 9/10, p. 155-176, jan./dez. 2008.

BARROS, Adriana Azevedo Paes de. Da televisão no Brasil ao televisinho em Cuiabá: aspectos históricos e a influência na Cuiabá dos anos 70. Cuiabá: Studio Press \& Multicolor Editores Associados, 1997. 
BARROS FILHO, Eduardo Amando. Por uma televisão cultural-educativa e pública: a TV Cultura de São Paulo, 1960-1974. Dissertação (Mestrado em História) - Universidade Estadual Paulista, Assis, 2010.

. A televisão educativa sob medida para o governo militar: a Fundação Centro Brasileiro de TV Educativa, 1964-1981. Tese (Doutorado em História) - Universidade Estadual Paulista, Assis, 2017.

BENJAMIN, Walter. Magia e técnica, arte e política: ensaios sobre literatura e história da cultura - v. I. 3. ed. São Paulo: Brasiliense, 1987.

BOURDIEU, Pierre. O poder simbólico. 3. ed. Rio de Janeiro: Bertand Brasil, 2000.

. Sobre a televisão. Rio de Janeiro: Jorge Zahar, 1997.

BUSETTO, Áureo. Imagens em alta indefinição: produção televisiva nos estudos históricos. In: GAWRYSZEWSKI, Aberto (org.). Imagens em debate. Londrina: Eduel, 2011. p. 161-177.

. (Org.). História plugada e antenada: estudos históricos sobre mídias eletrônicas no Brasil. Curitiba: Appris, 2017.

CAPARELLI, Sérgio. Televisão e capitalismo no Brasil. Porto Alegre: L\&PM, 1982.

COSTA, Osmani Ferreira da. A televisão e o palácio: concessões e desenvolvimento das emissoras e redes televisivas no Paraná (1954-1985). Tese (Doutorado em História) - Universidade Estadual Paulista, Assis, 2012.

FERREIRA, Cláudio. Cerrado em Close: Histórias dos primeiros anos da TV em Brasília. Brasília: Ler Editora, 2012.

FERREIRA, Jorge; GOMES, Ângela de Castro. 1964: o golpe que derrubou um presidente, pôs fim ao regime democrático e instituiu a ditadura militar no Brasil. Rio de Janeiro: Civilização Brasileira, 2014.

FICO, Carlos. Reinventando o otimismo: ditadura, propaganda e imaginário social no Brasil. Rio de Janeiro: Editora FGV, 1997.

GALETTI, Lylia da Silva Guedes. Nos confins da civilização: sertão, fronteira e identidade nas representações sobre Mato Grosso. Tese (Doutorado em História) - Universidade de São Paulo, 2000.

GODINHO, lúri Rincon. História da TV em Goiás. Goiânia: Contato Comunicações, 2008.

HAMBURGER, Esther. Diluindo fronteiras: a televisão e as novelas no cotidiano. In: SCHWARCZ, Lilian. História da vida privada no Brasil: contrastes da intimidade contemporânea - v. 4. São Paulo: Companhia das Letras, 1998. p. 440-487.

. O Brasil antenado: a sociedade da novela. Rio de Janeiro: Zahar, 2005.

JEANNENEY, Jean- Noël. Uma história da comunicação social. Lisboa: Terramar, 1996.

JORGE, Camila Dib Silva. A humanização da narrativa jornalística: a linguagem textual que aproxima o telespectador da notícia - O caso MS TV 1a edição. Dissertação (Mestrado em Estudos de Linguagens) - Fundação Universidade Federal de Mato Grosso do Sul, 2013.

KORNIS, Mônica Almeida. Uma história do Brasil recente nas minisséries da TV Globo. Tese (Doutorado em Comunicação) - Universidade de São Paulo, 2001. 
LEAL, Ondina Fachel. A leitura social da novela das oito. Petrópolis: Vozes, 1986.

LIMA, Eduardo de Campos. Formação da Rede Vida de Televisão: entre a política brasileira de concessões televisivas e as diretrizes católicas de comunicação social, 1989-1995. Dissertação (Mestrado em História) - Universidade Estadual Paulista, Assis, 2010.

LIMA, Mariana Mont'Alverne Barreto. TV Ceará: processo de modernização da cultura local. Dissertação (Mestrado em Sociologia) - Universidade Estadual de Campinas, 2003.

LION, Antonio Ricardo Calori de. Equipamentos cineteatrais: usos e simbolizações de espaços culturais nas capitais centro-oestinas no Estado Novo. Dissertação (Mestrado em História) Universidade Estadual Paulista, Assis, 2016.

MAIA, Paulo Roberto de Azevedo. Abertura: televisão e a luta pela democracia no Brasil (1979-1980). Tese (Doutorado em História) - Universidade Federal Fluminense, 2014.

MARTIN, Andrey Minin. Produzir energia, (pro)mover o progresso: o Complexo Hidrelétrico Urubupungá e os caminhos do setor energético. Tese (Doutorado em História) - Universidade Estadual Paulista, Assis, 2016.

MARTINS, Gerson Luiz. O poder na indústria midiática de Mato Grosso do Sul. Tese (Doutorado em Ciências de Comunicação) - Universidade de São Paulo, São Paulo, 1999.

MIRANDA, Luciano. Pierre Bourdieu e o campo de comunicação: por uma teoria da comunicação praxiológica. Porto Alegre: Edipucrs, 2005.

MORAIS, Fernando. Chatô: o rei do Brasil, a vida de Assis Chateaubriand. São Paulo: Companhia das Letras, 1994.

MOURÃO, Lucas Marinho. O meio rural sul-mato-grossense na televisão local: a produção jornalística do programa MS Rural. Dissertação (Mestrado em Comunicação) - Fundação Universidade Federal de Mato Grosso do Sul, 2013.

MUSSOLIN NETO, João. A televisão brasileira. São Paulo: CCSP, 1988.

OLIVEIRA, Lúcia Maciel Barbosa de. "Nossos comerciais, por favor!": a televisão brasileira e a Escola Superior de Guerra - o caso Flávio Cavalcanti. São Paulo: Beca Produções Culturais, 2001.

OLIVEIRA, Wellington Amarante. Telecurso $2^{\circ}$ grau: paradigma no ensino pela TV e legitimação política da Rede Globo, 1978-1981. Dissertação (Mestrado em História) - Universidade Estadual Paulista, Assis, 2011.

Muito além do conhecimento: a TV Educativa na França e no Brasil. Tese (Doutorado em História) - Universidade Estadual Paulista, Assis, 2017.

PALHA, Cássia Rita Louro. A Rede Globo e o seu repórter: imagens políticas de Teodorico a Cardoso. Tese (Doutorado em História) - Universidade Federal Fluminense, 2008.

QUEIROZ, Adolpho. TV de papel: a imprensa como instrumento de legitimação da televisão. 2. ed. Piracicaba: Editora Unimep, 1993. 
REDE GLOBO. TV Morena: história que começou a ser contada há mais de 45 anos (10 mar. 2017). Disponível em: <https://redeglobo.globo.com/tvmorena/noticia/tv-morena-historia-que-comecou-aser-contada-ha-mais-de-45-anos.ghtml>. Acesso em: 17 jan. 2018.

SALGUEIRO, Eduardo de Melo. "O maior projeto em prol de Mato Grosso": uma análise da revista Brasil-Oeste (1956-1967). Dissertação (Mestrado em História) - Universidade Federal da Grande Dourados, 2011.

SOARES, Marcelo Vicente Câncio. As emissoras, os jornalistas e os telejornais. In: Anais do IV Encontro Nacional de História da Mídia, 2006, São Luiz. CD do IV Encontro Nacional de História da Mídia, 2006.

Televisão fronteiriça: TV e telejornalismo na fronteira do Brasil e Paraguai. Campo Grande: Editora da UFMS, 2011.

SOTANA, Edvaldo Correa. Integração nacional, política e emissoras televisivas nos primeiros anos do regime militar: apontamentos sobre o surgimento da TV Morena. In: FERNÁNDEZ, Jorge Christian; MUSSI, Vanderléia Paes Leite; QUEIRÓZ, Vivina Dias Sol (org.). 1964, cinquenta anos: descomemorando a(s) ditadura(s) de segurança nacional sob a mira crítica da história e da educação. Campo Grande: Editora da UFMS, 2014. p. 99-120.

Emissoras televisivas de Campo Grande (MS): alguns apontamentos sobre fontes e a produção acadêmica. In.: BUSETTO, Áureo (Org.). História plugada e antenada: estudos históricos sobre mídias eletrônicas no Brasil. Curitiba: Appris, 2017. p. 137-154.

TONIAZZO, Gladis Salete Linhares. Caminhos da informação na Rede Matogrossense de televisão. Campo Grande: Editora Uniderp, 2007.

ZAHRAN, Jorge Elias. TV Morena: sua história. Arca - Revista do Arquivo Histórico de Campo Grande, n. 01. Campo Grande, 1990. 